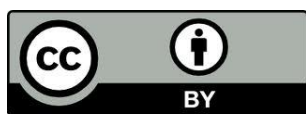

\title{
Novas Tecnologias de Informação e Comunicação no Ensino Religioso: Uma Proposta Metodológica via World Wide Web, na Escola de Aplicação da UFPA
}

New Technologies of Information and Communication in Religious Education: A Methodological Proposal via the World Wide Web, the School of Application of UFPa

Devison Amorim do Nascimento

Licenciado Pleno em Ciências da Religião e Especialista em Docência da Educação Superior pela Universidade do Estado do Pará (UEPA). Especialista em Educação para Relações Étnico-Raciais pelo Instituto Federal de Educação, Ciência e Tecnologia do Pará (IFPA). Especialista em Gestão Pública pela Universidade Federal do Pará (UFPA). Professor de Ensino Religioso da Escola de Aplicação da UFPA (EA-UFPA). Professor de Ensino Religioso da Secretaria Executiva de Educação do Pará (SEDUC-PA). dan@ufpa.br. devisonascimento@gmail.com.

RESUMO: O propósito desta comunicação é socializar uma proposta de Ensino Religioso mediado pelas Novas Tecnologias de Informação e Comunicação (TICs), disponíveis na World Wide Web, em processo de desenvolvimento na Escola de Aplicação da Universidade Federal do Pará (EA-UFPA). Explana-se como as redes sociais e outras ferramentas disponíveis na Web estão sendo canalizadas para auxiliar no desenvolvimento dos processos de ensino e de aprendizagem do Ensino Religioso na Escola de Aplicação.

Palavras-Chave: Ensino Religioso. Proposta Metodológica. World Wide Web. Escola de Aplicação da UFPA.

ABSTRACT: The purpose of this communication is to socialize a proposal for Religious Education mediated by New Information and Communication Technologies (ICTs), available on the World Wide Web, under development at the School of Application of the Federal University of Pará (UFPA-EA). Explains as social networks and other tools available on the web are being channeled to assist in the development of teaching and learning of Religious Education in the School of Application.

Keywords: Religious Education. Methodological Proposal. World Wide Web School Application UFPA. 
Notas sobre as Novas Tecnologias de Informação e Comunicação no Ensino Religioso

A história vem registrando profundas mudanças sociais e tecnológicas. E nesse contexto, não se pode tomar como novidade o constante melhoramento das tecnologias de informação e comunicação, as chamadas TICs, ferramentas que facilitam de maneira indiscutível a disseminação de informações/conhecimentos e a comunicação entre os atores de sociedades diversas do globo. As pessoas agora nascem e crescem em meio a uma avalanche de recursos tecnológicos, fazendo parte, como dizem Veen e Vrakking apud Campos e Silveira (2010), de uma geração chamada homo zappiens ou geração Z; e, sendo, como salienta Prensky apud Campos e Silveira (2010) uma geração de nativos digitais. Hoje as pessoas (os alunos) estão constantemente conectadas em rede e participam de comunidades virtuais diversas (Orkut, Facebook, Twiter e outras), conseguindo realizar várias tarefas ao mesmo tempo (estudar, "bater-papo", discutir temas importantes, fazer arte...).

Autores diversos vêm salientando que a educação e seus processos de ensino e aprendizagem devem acompanhar o "boom" tecnológico do mundo contemporâneo, transformando as TICs em poderosas ferramentas metodológicas nos processos educacionais. Segundo Terra (2012a), os jovens brasileiros são os que mais gastam tempo na Web, mais especificamente em redes sociais, ficando atrás somente dos jovens dos Estados Unidos e do Japão. O objetivo maior da juventude em estar em rede é o de se comunicar com outros, encontrar antigos amigos, manter relações com amigos presentes e fazer novas amizades, com as quais trocam informações, compartilham ideias, promovem e divulgam eventos, numa maneira dinâmica de encontrar entretenimento. Porém, para um hábil 
educador, as redes sociais e demais recursos da World Wide Web podem ir além de canais de entretenimento, criando metodologias de ensino e de aprendizagem que permitam conhecer melhor os seus alunos e, consequentemente, promover o melhoramento dos processos educacionais.

Moran (2007) salienta a necessidade de uma pedagogia flexível, integrada, inovadora e até experimental, para lidar com situações de aprendizagens diferentes, já que não há mais espaço para aulas meramente informativas e de caráter expositivo. O uso das Novas Tecnologias de Informação e Comunicação vem sendo experimentado em diversas áreas de conhecimentos, em diferenciadas disciplinas do Desenho Curricular das escolas, em busca de uma resposta satisfatória no que tange ao acompanhamento dos processos de ensino e de aprendizagem ao constante aperfeiçoamento das TICs.

Convém que o Ensino Religioso, como parte integrante da formação básica do cidadão e disciplina constituinte dos horários normais das escolas públicas de ensino fundamental, se engaje nessa nova proposta metodológica: a de se trabalhar os conteúdos da disciplina por meio das Novas Tecnologias de Informação e Comunicação. Dessa maneira, este texto tem como objetivo socializar a proposta metodológica de desenvolvimento do Ensino Religioso na Escola de Aplicação da Universidade Federal do Pará (EA-UFPA), para o ano letivo de 2013.

\section{O Google Docs como Ferramenta de Agenda e Orientações aos Alunos}

O Google Docs é uma ferramenta de compartilhamento de documentos que incluem textos, planilhas, apresentações de slides, formulários e até mesmo desenhos. 
Assim, uma das estratégias em utilização é a criação de agendas no Google Docs (uma agenda para cada turma), na qual o educador anotará as atividades e as orientações referentes à disciplina, que ficarão disponíveis na Web para que os estudantes possam acompanhá-las em qualquer lugar em que estiverem e se manterem a par das atividades e orientações. Para isso, todos os alunos das turmas devem estar cadastrados nos grupos.

Dessa maneira, as informações são restritas somente aos partícipes da disciplina, que também podem fazer anotações no Docs.

\section{O Twiter como Ferramenta de Divulgação Preliminar de Assuntos a serem Tratados em Sala de Aula}

O Twiter é utilizado como ferramenta de divulgação de assuntos a serem estudados em aulas próximas, inclusive com compartilhamento de materiais para estudo preliminar. Tal estratégia permite que os estudantes, na medida do possível, cheguem à sala de aula com conhecimentos/questionamentos sobre o que leu ou assistiu preliminarmente.

3 O Facebook como Ferramenta de Grupos de Estudos e Postagem de Materiais Complementares/Reforço

O Facebook é utilizado com a finalidade de fomentar e mediar grupos de estudos, com discussão intensiva entre os partícipes da disciplina, inclusive repassando conteúdos complementares ou de reforço sobre assuntos já discutidos em sala de aula. É interessante que seja criada uma página específica para cada turma, dada a diferenciação de assuntos entre anos/séries. Isso possibilitará também um acompanhamento mais eficaz dos grupos criados.

\section{O Blog como Ferramenta de Diário de Bordo}


O Blog é utilizado como uma ferramenta de armazenagem de materiais produzidos pelos alunos em sala de aula. É aproveitado também como um diário de bordo no qual o aluno registra suas impressões sobre o Ensino Religioso na Escola: como está sendo desenvolvido, o que está sendo interessante, o que poderia melhorar, que ações poderiam ser desenvolvidas, com vista a complementar os processos de ensino e de aprendizagem referente à disciplina. Por meio do Blog de cada estudante o professor - e a Direção da Escola - podem acompanhar o desempenho do aluno e o seu próprio desempenho, expressos nos relatos dos discentes registrados no Blog.

\section{O Youtube como Ferramenta de Armazenagem de Trabalhos Produzidos pelos Estudantes}

O Youtube é uma ferramenta disponível na Web com a finalidade de armazenar vídeos de naturezas diversas. Com efeito, muitos vídeos com fins educativos encontram no Youtube um canal de difusão muito eficiente. Assim, faz parte da proposta metodológica de Ensino Religioso na Escola de Aplicação da UFPA a produção de microdocumentários sobre a Diversidade e o Pluralismo Religioso do Brasil e da Amazônia, para armazenagem no Youtube e divulgação nos Blogs, páginas do Facebook e outras ferramentas utilizadas para o desenvolvimento da disciplina. Ressalta-se que os microdocumentários serão produzidos pelos estudantes, sob orientação do professor.

\section{Os Ambientes Virtuais de Aprendizagem (AVAs) como Ferramenta de Avaliação}

Os Ambientes Virtuais de aprendizagem (AVAs) são plataformas de ensino e de aprendizagem que possuem a finalidade de desenvolver cursos 
de Educação a Distância (EaD), uma modalidade de ensino que cresce em todo o mundo dada sua comprovada eficiência, somando-se de maneira imensurável com a Educação Tradicional ou Presencial.

Embora seja semelhante a um site, suas funções são bem mais avançadas, pois permitem acondicionar materiais diversos como textos, vídeos, arquivos de áudio e desenvolver ferramentas para a proposição de atividades aos partícipes dos cursos na modalidade a distância. Existem diversificados Ambientes Virtuais de Aprendizagem, cada Instituição de Ensino adota o que mais convém às suas propostas educacionais.

Sendo uma Instituição Federal de Ensino Superior (IFES), pioneira em ofertar cursos a distância na Região Norte, a UFPA trabalha com o Modular Object-Oriented Dynamic Learning Environment (Moodle), um software livre, de apoio ao desenvolvimento de cursos a distância. Não somente os cursos na modalidade EaD trabalham com o Moodle, mas muitos cursos presenciais tem adotado o referido AVA para o desenvolvimento de algumas de suas disciplinas, seja no âmbito da disponibilização de materiais, seja no âmbito da avaliação dos discentes.

Nesta proposta de Ensino Religioso via Web, o Moodle é utilizado para se trabalhar alguns conteúdos (textos, vídeos e arquivos de áudio), bem como promover a avaliação geral dos processos de ensino e de aprendizagem na disciplina, por meio de atividades dinâmicas e lúdicas que o AVA possibilita desenvolver.

\section{Considerações Finais}

O objetivo desta comunicação foi de apresentar a proposta metodologia em implementação para o Ensino Religioso na Escola de Aplicação da UFPA, no ano letivo de 2013. O que apresentamos aqui foi apenas uma síntese de tantas outras possibilidades de utilizar as Novas 
Tecnologias de Informação e Comunicação para o desenvolvimento do Ensino Religioso Escolar.

Não existe uma fórmula pronta, com vista a desenvolver uma proposta completa de Ensino religioso via World Wide Web. As escolas e os professores têm a autonomia de construir suas propostas com base na realidade de seu locus de trabalho, levando em consideração as condições de trabalho, o perfil social dos estudantes e outros aspectos. Por isso, para que uma proposta como essa seja desenvolvida se faz necessária primeiramente a realização de um diagnóstico do campo de trabalho e de seus atores sociais.

É preciso salientar que trabalhar em rede é compromisso de seriedade colossal. Antes do início do trabalho na Web, o professor precisa estabelecer Normas, deixando claro aos alunos as regras e os objetivos da interação educacional nas redes sociais e outros recursos da Web, delimitando o comportamento e os resultados a serem atingidos com o estudo do Ensino Religioso via World Wide Web. Acreditamos que se o trabalho em rede for bem mediado, o Ensino Religioso dará mais um importante passo rumo à sua consolidação definitiva no Desenho Curricular das Escolas, extinguindo assim margens de questionamentos sem fundamentos sobre a identidade da disciplina.

\section{Referenciais}

CAMPOS, Márcia de Borba. SILVEIRA, Milene Selbach. Práticas em Informática na Educação: Minicursos do Congresso Brasileiro de Informática na Educação, Volume 1, Número 1, 2010. Disponível em $<$ http://www.brie.org/pub/index.php/pie/article/viewFile/1310/1141>Acesso: 01/07/2011.

MORAN, J.M. A educação que desejamos: novos desafios e como chegar lá. Campinas, São Paulo: Papirus, 2007. 
TERRA, Rafael. Redes Sociais e Educação. Disponível em: < http://www.slideshare.net/FabulosaIdeia/redes-sociais-e-educao-15534954>. Acesso: 26.04.2013. a.

Estatísticas do Comportamento em Redes Sociais. Disponível em $<$ http://www.slideshare.net/FabulosaIdeia/estatisticas-do-comportamento-de-usuriosem-redes-sociais>. Acesso: 26.04.201. b.

\section{Bibliografia Consultada:}

ELIASQUEVICI, Marianne Kogut. FONSECA, Nazaré Araújo da. Educação a Distância: Orientações para o início de um percurso. Belém: EDUFPA, 2004.

PALLOFF, R.M.; PRATT, K. Construindo comunidades de aprendizagem no ciberespaço. Porto Alegre: Artmed, 2002.

PASSOS, João Décio. Ensino Religioso: Construção de uma Proposta. São Paulo: Paulinas, 2007. - (Coleção Temas do Ensino Religioso).

Recebido:15/04/2013

Received: 04/15/2013

Aprovado: 04/07/2013

Approved: 07/04/2013 